\title{
The effect of Mirabegron and Duloxetine combination in mixed-type urinary incontinence treatment
}

\author{
Ahmet Ariman ${ }^{1 *} \odot$, Erkan Merder ${ }^{1} \odot$, Mehmet Gökhan Çulha'
}

\section{SUMMARY}

OBJECTIVE: Stress-type and urgency-type urinary incontinence are seen together in mixed-type urinary incontinence. Treatment is usually chosen according to the predominant type of incontinence. The aim of this study is to evaluate the effect of mirabegron and duloxetine combination in the treatment of mixed-type urinary incontinence.

METHODS: The data of 88 mixed-type urinary incontinence patients who applied to the urology outpatient clinic between January 2018 and December 2019 were retrospectively analyzed. We applied mirabegron and duloxetine treatment to the patients. The International Consultation of Incontinence Questionnaire-Short Form, Overactive bladder symptom score questionnaire and daily pad count were statistically evaluated before and after the treatment.

RESULTS: Statistically significant improvements were observed using the questionnaire forms and decreased daily pad usage after the eight-week treatment $(p<0.001)$. Based on the clinical global effect scale, $62.50 \%$ of patients had a partial or complete response to treatment and also the use of daily pads were decreased from 3.7-0.89 on an average.

CONCLUSION: Combination use of mirabegron and duloxetine in the treatment of mixed-type urinary incontinence improved symptom scores and decreased pad usage.

KEYWORDS: Urinary incontinence. Mirabegron. Duloxetine hydrochloride.

\section{INTRODUCTION}

Urinary incontinence (UI) is defined as the complaint of involuntary loss of urine ${ }^{1}$ and is one of the four most important problems of elderly patients according to the World Health Organization $^{2,3}$. It is more common in women. Epidemiological studies have reported its prevalence between $25-45 \%{ }^{4}$. Although it is not a life-threatening situation, UI negatively affects patients, their families, and their environment physically, psychologically, and economically.

UI is categorized as stress urinary incontinence (SUI, incontinence due to physical exertion, coughing, and laughing), urgency urinary incontinence (UUI, involuntary UI with a sense of urgency), and mixed-type urinary incontinence (MUI, both sense of urgency and incontinence with physical exertion). SUI is more common in young and middle age women and is seen in $10-12 \%$ of women in this age group 5 . The prevalence of UUI and MUI is between $8-30 \%$ and is more common in people aged 65 and above ${ }^{2}$.

The type of UI can be diagnosed by the patient's history and bladder diary. Physical examination, urine analysis and culture, and residual urine volume measurement are among the basic tests.

Measures such as weight loss in obese patients, restriction of excessive fluid intake, and restriction of beverages such as

'Prof. Dr. Cemil Tașcıoğlu City Hospital - Șișli, Istanbul.

*Corresponding author: ahmetariman1@gmail.com

Conflicts of interest: the authors declare there is no conflicts of interest. Funding: none.

Received on February 14, 2021. Accepted on March 09, 2021. 
tea, coffee, and alcohol may be useful in the treatment of $\mathrm{UI}^{6,7}$. However, often medical or surgical treatment may be required.

Duloxetine is the only drug that increases urethral striated sphincter activity used in the treatment of SUI according to the systematic review result. It reduces the frequency of incontinence by $50 \%$ during the treatment process and provides a significant improvement in quality of life ${ }^{8}$.

Patients receiving antimuscarinic therapy for pure UUI usually have a positive response to this treatment. Mirabegron, a selective $\beta 3$-adrenoreceptor agonist, is an alternative in patients who discontinue antimuscarinics due to lack of response or side effects. Phase 3, multicenter, randomized controlled trials have shown that mirabegron is more effective in the reduction of incontinence episodes and improvement of health-related quality of life compared to placebo ${ }^{9,10}$.

In our study group, we aimed to evaluate the effect of the duloxetine and mirabegron combination in MUI patients.

\section{METHODS}

The data of MUI patients who applied to the urology outpatient clinic between January 2018 and December 2019 were retrospectively analyzed after the approval of Prof. Dr. Cemil Taşcıoğlu City Hospital Ethics Committee. Among the 108 MUI patients evaluated, 88 patients were included in the study after applying the exclusion criteria. Our patients were evaluated with urine analysis, urine culture, ultrasonography (to determine post void residual urine volume), and clinical examination (abdominal, pelvic, and perineal) before treatment. Stress incontinence was demonstrated with the provocative stress (coughing) test in both supine and standing positions. UI was detected by questioning and predominant symptoms determined by the patient's history. If necessary, urodynamic evaluation was also performed on these patients. They were questioned about their quality of life and their desire for treatment. Of these, 50 patients had predominant urge-type MUI and 38 patients had stress-type MUI. Patients with only SUI or UUI were not included in this study. In total, 20 patients with urinary infections, urinary tract stones, urinary malignancy, chronic obstructive pulmonary disease and patients who had undergone previous surgical treatment for UI, patients with grade 3-4 cystocele, prolapse, and patients with over $150 \mathrm{cc}$. residual urine volume were excluded from the study and urodynamic evaluation was performed.

Pretreatment demographic data, body mass index (BMI), daily pad count, International Consultation of Incontinence Questionnaire-Short Form (ICIQ-SF), overactive bladder symptom score (OABSS) questionnaire, and bladder diaries were recorded. Mirabegron $50 \mathrm{mg}$ (once a day) and duloxetine $40 \mathrm{mg}$ (twice a day) combination treatment was administered to MUI patients. After eight weeks of treatment, the patients were re-evaluated using the same forms and criteria. Pre and post treatment values were compared statistically. The clinical benefit of the patients was evaluated using the clinical global impact scale (CGI).

Power analysis was not done because study is unique. At least 75 patients were included for pilot studies.

\section{Statistical analysis}

SPSS 21.0 program (IBM, NY, USA) was used in statistical analysis. The distribution of variables was measured using the Kolmogorov-Smirnov test. The comparison of the questionnaire scores and the number of pads was evaluated by dependent sample $t$-test. A significant p-value was accepted as $<0.05$.

\section{RESULTS}

In our study group, 88 patients were between 42 and 70 years, with the mean age of $58.87 \pm 6.54$ years. BMI was between 19.85 and 35.42 with a mean value $28.95 \pm 5.32$. Table 1 shows patients data such as the number of birth and smoking history.

A total of 50 patients with dominant urge-type MUI did not completely respond to three month average antimuscarinic treatment. This was identified by questioning the symptoms of the patients (including three-day bladder diary). Another 38 patients with dominant stress-type MUI did not prefer surgical treatment, and they did not sufficiently benefit from three-month duloxetine treatment only. Before combination therapy, 18 of 50 patients (36\%) in the UUI group and 25 of 38 patients $(65 \%)$ in the SUI group performed pelvic floor muscle exercises (PFME) for two months, which did not provide enough benefit (Table 2).

After eight weeks of mirabegron $50 \mathrm{mg}$ (once a day) and duloxetine $40 \mathrm{mg}$ (twice a day) combination treatment, ICIQ-SF score decreased from 14.71 $\pm 3.54-7.83 \pm 6.41(\mathrm{p}<0.001)$ and OABSS from 11.00 $\pm 2.26-7.02 \pm 2.17(\mathrm{p}<0.001)$, and the number of pads per day decreased from $3.7 \pm 2.8-0.89 \pm 1.02$ $(\mathrm{p}<0.001)$. Pre and post treatment values are shown in Table 3 .

According to CGI, 55 out of 88 (62.50\%) patients had a partial or complete response from the treatment. In our study group, 80 patients adapted to the treatment and completed the eight-week process. In eight patients, side effects (three patients had dizziness and nausea, three patients had hypertension attacks, and two patients had jaw spasm) were observed and were returned to normal when the drug was discontinued. 
Table 1. Demographics of patients.

\begin{tabular}{l|c|c|c} 
& All & UUI & SUI \\
& 88 & 50 & 38 \\
\hline Age (Mean) & $42-70(58.87 \pm 6.54)$ & $54-70(63.61 \pm 5.6)$ & $42-65(50.85 \pm 5.8)$ \\
\hline Gender (F/M) & $88 / 0$ & & \\
\hline Smoking (+/-) & $40 / 48$ & $19 / 31$ & $21 / 17$ \\
\hline BMl (Mean) & $19.85-35.42(28.95 \pm 5.32)$ & $19.85-31.35(24.83 \pm 4.72)$ & $23.94-35.42(27.21 \pm 4.84)$ \\
\hline Primiparity & 82 & 44 & 38 \\
\hline Multiparity & 74 & 39 & 35 \\
\hline
\end{tabular}

UUI: urgency-type urinary incontinence; SUI: stress-type urinary incontinence; BMI: body mass index.

Table 2. Conservative treatments before combined drug therapy.

\begin{tabular}{l|c|c} 
& UUI & SUI \\
\hline PFME 88/43 & $50 / 18$ & $38 / 25$ \\
\hline Bladder training & $50 / 50$ & $38 / 38$ \\
\hline
\end{tabular}

PFME: pelvic floor muscle exercise; UUI: urgency-type urinary incontinence; SUI: stress-type urinary incontinence.

Table 3. Before and after treatment values of mixed-type urinary incontinence patients.

\begin{tabular}{l|c|c} 
& Before treatment & After treatment \\
\hline ICIQ-SF & $14.71 \pm 3.54$ & $7.83 \pm 6.41$ \\
\hline OABSS & $11.00 \pm 2.26$ & $7.02 \pm 2.17$ \\
\hline Daily pads & $3.7 \pm 2.8$ & $0.89 \pm 1.02$ \\
\hline$p<0.001$ & & \\
\hline
\end{tabular}

ICIQ-SF: international consultation of incontinence questionnaire-short form; OABSS: overactive bladder symptom score.

\section{DISCUSSION}

Treatment is planned after the basic evaluations of UI diagnosis and after excluding other concurrent underlying urinary system diseases. Conservative treatment methods such as PFMEs can be tried first for SUI ${ }^{11,12}$. A systematic review of 21 trials involving 1281 women (665 PFMT, 616 controls) showed that women in the PFMT groups were eight times more likely than controls to report that they were cured and 17 times more likely to report cure or improvement in UI ${ }^{13}$. Consequently, the International Consultation on Incontinence (ICI) recommends that PFMT should be considered as a first-line treatment in women with UI ${ }^{14}$. PFMT was applied to 43 patients in our study group as a first-line treatment, but they could not get a complete result. Surgery is also a treatment option with a high success rate for SUI. However, pharmacological therapy is the next option for SUI treatment.

Duloxetine, a serotonin-norepinephrine reuptake inhibitor, is the only pharmacotherapy option used in many countries for
SUI treatment. Although it reduces incontinence episode frequency by approximately $50 \%$, it is unclear whether the benefits are sustainable, and side effects such as nausea are common. Also, three patients in our group complained of nausea. Therefore, the persistence with duloxetine was affected due to side effects. In a study group of 588 women, patients were classified into SUI-predominant MUI, UUI-predominant MUI, or balanced MUI in a randomized controlled trial versus placebo. Duloxetine was effective in improving incontinence and incontinence-quality-of-life (I-QOL) in all subgroups ${ }^{15}$. However, the effect of topical estrogen use in elderly female patients is still controversial ${ }^{11,16,17}$. There is also some evidence to suggest that administration of local estrogens in conjunction with antimuscarinics could have a synergistic effect in the management of postmenopausal women with overactive bladder ${ }^{18}$.

Studies suggest that bladder training and PFME are the main treatment option for UUI in young women ${ }^{6,11}$. Antimuscarinic drugs are another option ${ }^{11}$. Suitable antimuscarinic drugs for 
UUI are oxybutynin, tolterodine, fesoterodine, solifenacin, darifenacin, propiverine, and trospium chloride. These are more effective than placebo, safe, and well-tolerated treatments that improve health-related quality of life ${ }^{19}$. Traditionally, side effects such as dry mouth, constipation, cognitive impairment, and sleep disturbance have limited the usefulness of antimuscarinic agents.

The rate of continuous use of antimuscarinic drugs is very low. The rate of patients who continue to use these drugs at the end of one year is only $12-39 \%{ }^{20}$. Side effects and treatment unresponsiveness have been reported as the main causes of withdrawal ${ }^{21}$. In a randomized controlled study conducted with a group of 854 women with MUI, it was observed that tolterodine was effective for the treatment of overactive bladder, but was not effective enough for SUI symptoms ${ }^{22}$. Similar results have been found for solifenacin ${ }^{23}$.

A selective $\beta 3$-adrenoreceptor agonist mirabegron might offer an alternative option for women not responding or facing serious side effects to antimuscarinics. The safety and tolerability of mirabegron were established over 12 months, with sustained efficacy observed over this treatment period ${ }^{24}$. Furthermore, in Canadian retrospective claims database study involving 19,485 patients, persistence at 12 months was 39\% for mirabegron versus $14-35 \%$ for antimuscarinics. Patients taking mirabegron demonstrated, statistically significant, greater adherence than those taking antimuscarinics ${ }^{25}$.

In this study, we used the combination of duloxetine and mirabegron in patients with MUI. We evaluated the ICOQ-SF,
OABSS forms, and daily pad counts, and we found statistically significant improvements after eight weeks of treatment ( $<<0.001)$. Despite the side effects (e.g., hypertension, nausea, and dizziness) seen in $0.9 \%$ of the patients, they were able to continue the treatments during eight weeks. We did not find enough publications in the literature regarding the usefulness of the combination of mirabegron and duloxetine in the treatment of MUI.

The study has some limitations. First, there is no control group. Patients were evaluated according to their symptoms before and after treatment. The short follow-up period of the patients is another limitation. Evaluation of MUI can only be relied on the story of patients is among the limitations of the study.

\section{CONCLUSION}

In our study, we have shown statistically that using mirabegron and duloxetine combination in patients with MUI improves symptom scores and decreases daily pad usage. Since our study sample size was small, larger randomized controlled study groups are needed to better evaluate the effectiveness.

\section{AUTHORS" CONTRIBUTIONS}

AA: Conceptualization, Data curation, Formal Analysis, Writing - review \& editing. MGÇ: Data curation. EM: Formal Analysis, Writing - review \& editing.

\section{REFERENCES}

1. Haylen BT, Ridder D, Freeman RM, Swift SE, Berghmans B, Lee J, et al. An International Urogynecological Association (IUGA)/International Continence Society (ICS) joint report on the terminology for female pelvic floor dysfunction. Neurourol Urodyn. 2010;29(1):4-20. https://doi.org/10.1002/nau.20798

2. Milson I, Coyne KS, Nicholson S, Kvasz M, Chen Cl, Wein AJ. Global prevalence and economic burden of urgency urinary incontinence: a systematic review. Eur Urol. 2014;65(1):79-95. https://doi.org/10.1016/j.eururo.2013.08.031

3. World Health Organization. WHO ageing and life course. Geneva: World Health Organization; 2014. [cited on Jun. 27, 2014]. Available from: https://www.who.int/health-topics/ ageing\#tab=tab_1

4. Milsom I, Altman D, Cartwright R, Lapitan MC, Nelson R, Sillén $\mathrm{U}$, et al. Epidemiology of urinary incontinence (UI) and other Lower Urinary Tract Symptoms (LUTS), Pelvic Organ Prolapse (POP) and Anal Incontinence (Al). In: Abrams P, Cardozo L, Khoury S, Wein AJ, editors. Incontinence: 5th International Consultation on Incontinence. Paris: ICUD-EAU; 2013. p. 15-107.
5. Giarents I, Mastoroudes H, Srikrishna D, Robinson D, Cardozo I. Is there a difference between women with or without detrusor overactivity complaining of symptoms of overactive bladder? BJU Int. 2013;112(4):501-7. https://doi.org/10.1111/j.1464410X.2012.11652.x

6. Abrams P, Andersson KE, Birder L, Brubaker L, Cardozo L, Chapple $C$, et al. Fourth International Consultation on Incontinence Recommendations of the International Scientific Committee: evaluation and treatment of urinary incontinence, pelvic organ prolapse, and fecal incontinence. Neurourol Urodyn. 2010;29(1):213-40. https://doi.org/10.1002/nau.20870

7. Swithinbank $L$, Hashim $H$, Abrams $P$. The effect of fluid intake on urinary symptoms in women. J Urol. 2005;174(1):187-9. https://doi.org/10.1097/01.ju.0000162020.10447.31

8. Mariappan P, Alhasso A, Ballantyn Z, Grant A, N'Dow J. Duloxetine, a serotonin and noradrenaline reuptake inhibitor (SNRI) for the treatment of stress urinary incontinence a systematic review. Eur Urol. 2007;51(1):67-74. https://doi. org/10.1016/j.eururo.2006.08.041 
9. Nitti WW, Auerbach S, Martin N, Calhaun A, Lee M, Herschorn $\mathrm{S}$. Results of a randomized phase III trial of mirabegron in patients with overactive bladder. J Urol. 2013;189(4):1388-95. https://doi.org/10.1016/j.juro.2012.10.017

11. Khullar V, Amarenco G, Angulo JC, Cambronero J, Høye K, Milsom I, et al. Efficacy and tolerability of mirabegron, a $\beta(3)$ adrenoreceptor agonist, in patients with overactive bladder: results from a randomized European-Australian phase 3 trial. Eur Urol. 2013;63(2):283-95. https://doi.org/10.1016/j. eururo.2012.10.016

12. National Institute for Health and Care Excellence. Urinary incontinence in women: management. Clinical guideline [CG 171]. Manchester: National Institute for Health and Care Excellence. [cited on Dec. 23, 2020]. Available from: https:// guidance.nice.org.uk/CG171

13. Shamliyan T, Wyman J, Kane RL. Nonsurgical treatments for urinary incontinence in adult women: diagnosis and comparative effectiveness [Internet]. Rockville (MD): Agency for Healthcare Research and Quality (US); 2012 Apr. Report No.: 11(12)-EHC074-EF. PMID: 22624162

14. Dumoulin C, Cacciari LP, Hay-Smith J. Pelvic floor muscle training versus no treatment, or inactive control treatments, for urinary incontinence in women. Cochrane Database Syst Rev. 2010;(1):CD005654. https://doi.org/10.1002/14651858. CD005654.pub2

15. Bradley C, Burgio K, Chambers T, Hagen S, Hunter K, Imamura $\mathrm{M}$, et al. Adult conservative management. In: Abrams P, Cardozo L, Khoury S, Wein AJ, (Eds.). Incontinence: 5th International Consultation on Incontinence. Paris: ICUD-EAU; 2013. p. $1101-228$

16. Bent $A E$, Gousse $A E$, Hendrix SL, Klutke CG, Monga AK, Yuen $C K$, et al. Duloxetine compared with placebo for the treatment of women with mixed urinary incontinence. Neurourol Urodyn. 2008;27(3):212-21. https://doi.org/10.1002/nau.20471

17. Shamliyan T, Wyman JF, Ramakrishnan R, Sainfort F, Kane RL. Benefits and harms of pharmacologic treatment for urinary incontinence in women: a systematic review. Ann Intern Med. 2012;156(12):861-74,W301-10. https://doi.org/10.7326/00034819-156-12-201206190-00436

18. Cody JD, Richardson K, Moehrer B, Hextall A, Glazener CM. Oestrogen therapy for urinary incontinence in post-menopausal women. Cochrane Database Syst Rev. 2009;(4):CD001405. https://doi.org/10.1002/14651858.CD001405.pub2

19. Tseng LH, Wang AC, Chang YL, Soong YK, Lloyd LK, Ko YJ. Randomized comparison of tolterodine with vaginal estrogen cream versus tolterodine alone for the treatment of postmenopausal women with overactive bladder syndrome. Neurourol Urodyn. 2009;28(1):47-51. https://doi.org/10.1002/ nau.20583

20. Chapple CR, Khullar V, Gabriel Z, Muston D, Bitoun CE, Weinstein $D$. The effects of antimuscarinic treatments in overactive bladder: an update of a systematic review and meta-analysis. Eur Urol. 2008;54(3):543-62. https://doi. org/10.1016/j.eururo.2008.06.047

21. Veenboer PW, Bosch JL. Long-term adherence to antimuscarinic therapy in everyday practice: a systematic review. J Urol. 2014;191(4): 1003-8. https://doi.org/10.1016/j.juro.2013.10.046

22. Benner JS, Nichol MB, Rovner ES, Jumadilova Z, Alvir J, Hussein $M$, et al. Patient-reported reasons for discontinuing overactive bladder medication. BJU Int. 2010;105(9):1276-82. https:// doi.org/10.1111/j.1464-410X.2009.09036.x

23. Khullar V, Hill S, Laval KU, Schiøtz HA, Jonas U, Versi E. Treatment of urge-predominant mixed urinary incontinence with tolterodine extended release: a randomized, placebocontrolled trial. Urology. 2004;64(2):269-74; discussion274-5. https://doi.org/10.1016/j.urology.2004.02.029

24. Kelleher C, Cardozo L, Kobashi K, Lucente V. Solifenacine: as effective in mixed urinary incontinence as in urge urinary incontinence. Int Urogynecol J Pelvic Floor Dysfunct. 2006;17(4):382-8. https://doi.org/10.1007/s00192-0050023-4

25. Chapple CR, Kaplan SA, Mitcheson D, Klecka J, Cummings J, Drogendijk T, et al. Randomized double-blind, active-controlled phase 3 study to assess 12-month safety and efficacy of mirabegron, a $\beta(3)$-adrenoceptor agonist, in overactive bladder. Eur Urol. 2013;63(2):296-305. https://doi.org/10.1016/j. eururo.2012.10.048

26. Wagg A, Franks B, Ramos B, Berner T. Persistence and adherence with the new beta-3 receptor agonist, mirabegron, versus antimuscarinics in overactive bladder: early experience in Canada. Can Urol Assoc J. 2015;9(9-10):343-50. https://doi. org/10.1016/j.jval.2014.08.1336 